\title{
RELATIONSHIP BETWEEN LOWER BODY ANAEROBIC POWER AND COMPETITIVE SWIMMING RESULTS OF BULGARIAN SWIMMERS
}

\author{
Mihail Kachaunov, Lubomir Petrov \& Lubomir Mladenov \\ National Sports Academy "Vassil Levski”, Sofia, Bulgaria
}

\begin{abstract}
The aim of this study was to find if there is a significant relationship between anaerobic power and freestyle swimming performance. The participants were 87 national and international level Bulgarian swimmers (37 women and $50 \mathrm{men}$ ). The average age was $15.45 \pm 1.49$ years: $15.05 \pm 1.55$ years for women and $15.74 \pm 1.40$ years for men. The determination of anaerobic power was made by standard Wingate anaerobic test protocol. Absolute and relative values of the main indicators of the test have been measured: Peak power (PP) and Average Power (AP). For the comparison have been chosen sprint freestyle swimming events (50 100 and $200 \mathrm{~m}$ ). Swimming times were taken from the official results of Bulgarian national swimming championship conducted 10 days after Wingate anaerobic test have been performed. As a result, we have found significant correlations between the main indicators of the Wingate anaerobic test and sprint freestyle performance for both women: $50 \mathrm{~m}$ vs. $P P(r=-0.600$; $p<0,001) ; 50 \mathrm{~m}$ vs. $A P(r=-0.668$; $p<0,001)$ and men: $50 \mathrm{~m}$ vs. $P P(r=-$ $0.789 ; p<0.001) ; 50 \mathrm{~m}$ vs. AP $(r=-0.847 ; p<0.001)$. The conclusion is that there is a significant correlation between the anaerobic power measured by Wingate anaerobic test and freestyle swimming performance. In addition, we can recommend Wingate anaerobic test as an appropriate method for assessment anaerobic power in swimmers.
\end{abstract}

Key words: Anaerobic power; Swimming; Wingate anaerobic test

\section{INTRODUCTION}

Most of the competitive swimming events (up to $200 \mathrm{~m}$ ) finish in about 2 minutes (Gullstrand, 2000). From all 32 disciplines of the official competition program for the last Olympic Games held in Rio, 2016 these lasting from $22-24$ s to 2 min also predominate. They are correspondingly with anaerobic and mixed energy contribution and therefore the achievements in those events mainly depends of the power of the two anaerobic energy systems (ATP-CP and anaerobic glycolysis) (Izov, 2017)

The anaerobic power can be assessed by different laboratory based tests. Various anaerobic cycle test which include a different duration and loadings have been described (Szogy, Cherebetiu, 1974; Sargeant, Davies 1977; Pirnay, Crielaard, 1979; Peres et al., 1981; Dushkov, Stefanova, 1983; Szogy, 1984), The most frequently used in sport practice is the Wingate anaerobic test (WAnT) created by the members of the sports medicine department of the Wingate institute, Israel (Inbar et al., 1996). The basic parameters of WAnT which characterize anaerobic performance are: the peak power (PP) the average power (AP) and the power drop (PD). It is considered that the peak power developed in the first seconds of the test is the results of the energy generated by adenosine triphosphate and creatine phosphate (ATP-CP) and serves to estimate the power of the ATP-CP system. In the other hand, the average power developed during the whole test is result predominantly of the glycolysis generated energy supply and serves to estimate the power of the anaerobic glycolytic system (Dotan, Bar-Or, 1983; Inbar et al., 1996; Lovell et al., 2013; Forbes et al., 2014). The fatigue index represents the ratio between the values of the peak power and the minimum power at the end of the test.

Some researches estimates the connection between the performance of the WAnT and swimming achievements. Hawley et al. (1992) ware investigating the relationship between the test parameters and swimming speed on 22 swimmers (10 women $-13.2 \pm 1.9$ years and 12 men $-13.6 \pm 1.2$ years) The researchers find a strong correlation between the velocity of $50 \mathrm{~m}$ freestyle and the average power (AP) $(r=0.76)$. In 1993 Duche et al. measured the speed in competitive swimming at 50 and $400 \mathrm{~m}$ and the PP and AP in the lower body Wingate anaerobic test in 25 swimmers - children aged $11.3 \pm 1.0$. The researchers find significant correla- 
tion relationships between $\mathrm{PP}$ and $\mathrm{AP}$ and speed of $50 \mathrm{~m}(\mathrm{r}=0.57 ; \mathrm{r}=0.51$ correspondingly $)$ and low correlation between PP and AP and speed of $400 \mathrm{~m}(\mathrm{r}=0.35 ; \mathrm{r}=0.15$ correspondingly). Resent researches Shimoyama et al. (2018) and Demarie et al. (2019) also made similar researches.

\section{Aim}

The aim of the study was to estimate the lower body anaerobic power of competitive Bulgarian swimmers, and its correlation with the freestyle swimming results.

\section{METHODS}

\section{Participants}

The participants were 86 ( 36 women and 50 men) competitive swimmers, members of the Bulgarian National Swimming Team. The mean age was 14.97 \pm 1.46 for the women and $15.64 \pm 1.37$ for the men. The heights of the participants were measured by a stadiometer with an accuracy of $0.5 \mathrm{~cm}$, and the weights by an electronic scale with an accuracy of $0.1 \mathrm{~kg}$. The competitive swimming performance was between 503 and 533 FINA points for women and 496 to 560 FINA points for men.

\section{Wingate anaerobic test}

A lower body Wingate anaerobic test was made using a mechanical cycle ergometer Monark" model 894E, Sweden designed for anaerobic tests and specialized software for it (Monark anaerobic test software) of the manufacturer. The power is determined by the resistance and the rotational speed (Driss, Vandewalle, 2013). To correctly determine the work don and the mechanical power the software calculates the change of the kinetic energy of the flywheel. Proportional to the change of its rotational speed and its moment of inertia witch the manufacturer gives as $0.91 \mathrm{~kg} . \mathrm{m}^{2}$.

For the test we used the protocol given by Inbar et al., (1996):

Preparation (worm up). Low intensity pedaling with a duration of three minutes of low resistance of $1 \mathrm{~kg}$ (the weight of the basket) at $60 \mathrm{rpm}$. At the end of the first and the second minutes sprints at maximal speeds and duration of 5 seconds are performed. Recovery - 3 min passive rest.

Main part: Pedaling without resistance for $10 \mathrm{~s}$, acceleration to maximum speed without resistance, test measurements with maximum intensity at a given resistance equal to $7.5 \%$ of the body mas, with a duration of $30 \mathrm{~s}$.

\section{CONCLUSIONS}

Low intensity pedaling without resistance for two minutes aim to maintain the work of the muscle pomp and precluding of appearance of pathological orthostatic reactions.

Many primary and derive parameters were calculated and used in our research: Peak Power - PP [W]; Relative Peak Power - RPP [W/kg]; Average Power - AP [W]; Relative Average Power - RAP [W/kg]; Minimum Power - MP [W]; Relative Minimum Power - RMP [W/kg]; Power Drop - PD [W]; Relative Power Drop - RPD [W/kg]; Power Drop - PD [\%]; Total work - TW [J].

\section{Statistics}

The statistical analysis was performed by the SPSS.19 statistical package (IBM, USA). Student's t-test for independent samples was used to find if there were statistically significant differences in the mean values of the measured parameters between men and women. To determine the connection between the anaerobic power and swimming results the Pearson Correlation test was used. To conclude that there are statistically significant correlations between the variables we have used the 2-Tailed significance value. The results are expressed as mean values \pm one standard deviation (SD) in the text and in the table representation and mean \pm standard error (SE) in the graphical representation of the data.

\section{RESULTS}

\section{Descriptive statistics}

Table 1. Descriptive statistics of women and men. shown the descriptive statistics of age, height, weight, Wingate anaerobic test results and competitive swimming times both for men and women. The average age of the women vs. men is significantly lower by 8 months. Men's average heights and weights vs. women are significantly higher with $10.63 \mathrm{~cm}$ and $10.46 \mathrm{~kg}$ respectively. In the three indicators the coefficient of variation was small (from $4.25 \%$ to $10.86 \%$ ) which shows strong uniformity in the group regarding age and the anthropometric indicators.

The mean values of all parameters of the anaerobic test apart from PD are significantly different for men and women. In this way the maximum, the average and the minimum power in men are higher than those for women respectively by $257.9 ; 175.0 ; 119.5 \mathrm{~W}$ for the absolute values and $2.44 ; 1.51 ; 1.02 \mathrm{~W} / \mathrm{kg}$ for the relative values. The drop in the absolute and relative power is higher in men respectively with $138.47 \mathrm{~W}$ 
and $1.44 \mathrm{~W} / \mathrm{kg}$. The average difference in total work range between $10.69 \%$ и $25.72 \%$, the lowest been that between women and men is $5197.7 \mathrm{~J}$. The coefficient of variation of the absolute values of the anaerobic test indicators for both sexes was between $16.8 \%$ and $28.20 \%$ (uniform sample) and it was smallest for the average power and highest for the power drop. The coefficients of variation for the relative indicators

for the RAP and the highest RPD for

The gender differences in freestyle swimming times were $3.16 \mathrm{~s}$ for $50 \mathrm{~m}, 7.00 \mathrm{~s}$ for $100 \mathrm{~m}$ and $15.62 \mathrm{~s}$ for $200 \mathrm{~m}$. Comparing FINA points between women and men the differences are 507 vs. 496 for $50 \mathrm{~m}$ 504 vs. 513 for $100 \mathrm{~m}$ and 533 to 560 for $200 \mathrm{~m}$.

Table 1. Descriptive statistics of women and men.

\begin{tabular}{|l|c|c|c|c|c|c|c|c|}
\hline \multirow{2}{*}{ Variables } & \multicolumn{3}{|c|}{ Women } & \multicolumn{3}{c|}{ Men } \\
\cline { 2 - 9 } & $\mathrm{n}$ & $\min$ & $\max$ & mean \pm SD & $\mathrm{n}$ & $\min$ & $\max$ & mean \pm SD \\
\hline Age & 36 & 13.0 & 18.0 & $14.97 \pm 1.46^{*}$ & 50 & 13.0 & 18.0 & $15.64 \pm 1.37$ \\
\hline Height [cm] & 36 & 156.0 & 180.0 & $167.19 \pm 7.10 \#$ & 50 & 161.0 & 194.0 & $177.82 \pm 7.46$ \\
\hline Weight [kg] & 36 & 45.7 & 67.5 & $57.76 \pm 6.27 \#$ & 50 & 48.15 & 81.67 & $68.22 \pm 7.63$ \\
\hline PP [W] & 36 & 272.4 & 727.3 & $512.8 \pm 111.96 \#$ & 50 & 451.8 & 1047.0 & $770.8 \pm 146.32$ \\
\hline RPP [W/kg] & 36 & 4.60 & 10.87 & $8.83 \pm 1.39 \#$ & 50 & 7.70 & 14.40 & $11.27 \pm 1.58$ \\
\hline AP [W] & 36 & 234.4 & 560.1 & $398.5 \pm 79.57 \#$ & 50 & 335.5 & 737.8 & $573.5 \pm 95.60$ \\
\hline RAP [W/kg] & 36 & 4.00 & 8.30 & $6.87 \pm 0.95 \#$ & 50 & 5.70 & 9.70 & $8.38 \pm 0.90$ \\
\hline MP [W] & 36 & 146.4 & 413.0 & $274.8 \pm 61.97 \#$ & 50 & 199.5 & 535.9 & $394.3 \pm 72.90$ \\
\hline RMP [W/kg] & 36 & 2.50 & 6.10 & $4.74 \pm 0.85 \#$ & 50 & 4.20 & 6.90 & $5.76 \pm 0.73$ \\
\hline PD [W] & 36 & 126.0 & 346.5 & $238.0 \pm 63.97 \#$ & 50 & 166.5 & 613.1 & $376.5 \pm 106.19$ \\
\hline RPD [W/kg] & 36 & 2.10 & 6.10 & $4.08 \pm 0.87 \#$ & 50 & 3.10 & 9.30 & $5.52 \pm 1.42$ \\
\hline PD [\%] & 36 & 33.40 & 56.50 & $46.22 \pm 5.82$ & 50 & 32.6 & 65.6 & $48.4 \pm 7.05$ \\
\hline TW [J] & 36 & 7009 & 16706 & $11763 \pm 923.9 \#$ & 50 & 9918 & 21831 & $16961 \pm 2831.8$ \\
\hline 50 m & 36 & 26.57 & 30.02 & $28.75 \pm 0.89 \#$ & 50 & 23.59 & 29.37 & $25.59 \pm 1.56$ \\
\hline $\mathbf{1 0 0}$ m & 27 & 55.65 & 68.59 & $63.12 \pm 3.34 \#$ & 46 & 50.99 & 63.62 & $56.12 \pm 3.74$ \\
\hline $\mathbf{2 0 0}$ m & 23 & 123.88 & 148.42 & $136.17 \pm 6.31 \#$ & 36 & 112.48 & 133.46 & $120.55 \pm 5.70$ \\
\hline
\end{tabular}

* $p<0.05$ vs men; \# $-p<0.001$ vs men

\section{Correlations}

The anthropometric parameters, the results of the lower body WAnT and the swimming achievements of the tested women are included in the correlational analysis. A natural significant correlation between the age and the height of the participants $(\mathrm{r}=0.551 ; \mathrm{p}<0.001)$ and between the age and the weight $(r=0.609 ; p<0.001)$ is observed. We found positive correlation of the weight with the absolute indicators of the test (PP and AP), the highest being that with AP $(r=0.747 ; \mathrm{p}<0.001)$. The relative indicators showed no reliable correlation with weight. The relative and the absolute indicators of the test show significant correlations with the swimming achievements only for $50 \mathrm{~m}$ freestyle the highest been that for the absolute indicator AP ( $\mathrm{r}$ $=-0.660 ; \mathrm{p}<0.001)$. The sprint swimming events $(50,100$ и $200 \mathrm{~m})$ show high mutual correlation between 0.746 and 0.858 .

The anthropometric parameters, the results of the lower body WAnT and the swimming achievements of the tested men are included in the correlational analysis. As for women a natural correlation exist between the age and the height of the participants $(\mathrm{r}=0.570 ; \mathrm{p}<0.001)$ and between the age and the weight $(r=0.486 ; p<0.001)$. Reliable correlation relationships exists between the absolute indicators of the Wingate anaerobic test and the age height and weight. The highest correlation is between the average power (AP) and the weight $(r=0.777$; $\mathrm{p}<0.001)$. Significant correlation relationships are found between the age and relative indicators of the test the highest been that with relative average power (RAP) $(r=0.588 ; p<0.001)$. Reliable high correlation exists between the Wingate anaerobic test indicators and swimming achievements in 50, 100 and $200 \mathrm{~m}$, the highest been that for $50 \mathrm{~m}$ and average power $(r=0.859 ; p<0.001)$. Between achievements in the three sprint events we observed expected height correlations. The Wingate test indicators also show height natural correlation.

\section{Regression}

A linear multiple stepwise regression analysis was done to estimate the influence of the studied indicators for the anaerobic performance on the achievements for $50 \mathrm{~m}$ freestyle separately for the two genders. The stepwise regression include as 
independent values the indicators of the Wingate evements (PP, RPP, AP и RAP), as well as the age, test witch correlate most strongly with the achi- height and the mass of the competitors.

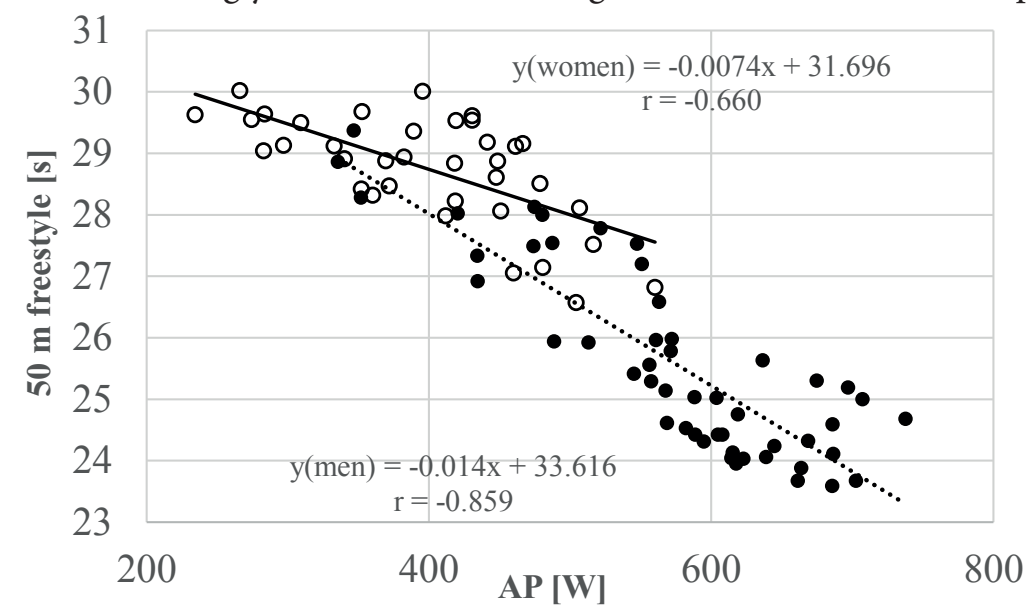

Figure 1. Graphic representation of the linear regression equation for the relationship between the swimming achievements and the average power AP developed during the Wingate anaerobic test for women

(blank circle and continuous line) and men (black dot and dotted line)

The stepwise regression analysis for women in- tion the absolute average power (AP) shown in Figcludes as the only variable in the regression equa- ure 1 . The regression equation is as follows:

$$
\text { Time }_{50 m}=-0.0074 * A P[W]+31.696(r=-0.660 ; p<0.001)
$$

The stepwise regression analysis for men also in- the absolute average power (AP) shown in Figure 1. cludes the only variable in the regression equation The regression equation is as follows:

$$
\text { Time }_{50 m}=-0.0227^{\star} A P[W]+33.576(\mathrm{r}=-0.859 p<0.001)
$$

\section{DISCUSSION}

For both women and men the relative indicator of anaerobic performance has a lower coefficient of variation than in the corresponding absolute indicators. This is due to the fact that in the relative indicators the variation due to weight differences has been removed. The indicators of the swimming achievements in 50, 100 и $200 \mathrm{~m}$ freestyle for women and men vary in a small range between 496 и 560 FINA points and correspondingly have a very low coefficient of variation of $3.10 \%$ to $6.67 \%$. This shows a strong uniformity of the sample in relation to sports results of the swimmers. The achievements of the women in 50, 100 and $200 \mathrm{~m}$ freestyle are lower than those in men by factors 1.12, 1.12 and 1.13 respectively. This difference corresponds to the $22 \%$ higher average power of men vs. women having in mind the nonlinear relationship between the power and swimming speed.

The correlation analysis for both genders shows reliable positive correlation of age with the height and weight which is a result of natural developmental process in women and men in the studied age range. Reliable high internal correlation relationships were found both among the results of the anaerobic test and among the swimming results for both genders, but the relative indicators (RPP и RAP) do not have any reliable correlation with weight since his influence has been removed in the calculation of these indicators. Among the WAnT' indicators the highest correlation with the $50 \mathrm{~m}$ freestyle swimming results for both genders is the average power (AP) for women $r=-0.660(p<0.001)$ and for men $r=-0.859(p<0.001)$. Other researchers also show average power as the indicator with highest correlation with swimming achievements (Demarie et al., 2019). In other studies the highest correlations have been established with the relative average power (RAP) Hawley et al., 1992) and with the peak power (PP) (Duche et al., 1993). The smaller correlation with RAP with $50 \mathrm{~m}$ freestyle swimming achievements $-r=-0.545(p<0.001)$ for women and $r=$ $-0.669(\mathrm{p}<0.001)$ for men can be explained with some residual influence of age and height. Similar to the results of other researches (Duche et al., 1993) with the increase of the swimming distance the relationship between the anaerobic test indicators and swimming achievements decreases. This is due to the lower contribution of the anaerobic glycolytic system in 100 and $200 \mathrm{~m}$ and increasing 
share of the aerobic system especially in $200 \mathrm{~m}$. The time for competitive swimming on $50 \mathrm{~m}$ freestyle is similar to the time for execution of the anaerobic test (30 s) so we have similar distributed shares of energy systems in the relation of the total energy consumption.

In the linear stepwise regression between the $50 \mathrm{~m}$ achievements and basic WAnT indicators only the $\mathrm{AP}$ is included in the regression equation for both women and men (Figure 1). The average power values who responds to points above the relevant regression lines show poor correspondence between the average power measured and the swimming achievements most likely due to the less than average swimming efficiency in freestyle. For these swimmers an in depth biomechanically analysis of their swimming technique and must be taken appropriate measures for improvement of its effectiveness can be recommended.

The competitors whose $50 \mathrm{~m}$ freestyle achievements correspond to points below the relevant regression lines in Figure 1 most likely have a more effective than the average freestyle technique. For these swimmers it can be recommended to be included specific or unspecific methods and means for improving the anaerobic power in the lower body.

\section{CONCLUSIONS}

Reliable correlation relationships exist between the results of the lower body Wingate anaerobic test and swimming achievements, the highest one been with average power.

The regression equation describing the connection between the average power of the anaerobic test and the swimming achievements can provide additional information for the direction for future training activity - prenominal technique improvement of swimmers or more work for developing anaerobic power.

\section{REFERENCES}

Demarie, S., A. Chirico, A. Gianfelici, and G. Vannozzi. (2019). Anaerobic Capacity Assessment in Elite Swimmers Through Inertial Sensors. Physiol Meas. Epub ahead of print, doi: 10.1088/1361-6579/ab205d

Dotan, R., O. Bar-Or. (1983). Load Optimization for the Wingate Anaerobic Test. Eur J Appl Physiol. Vol. 51, pp. 409-417

Driss, T., H. Vandewalle. (2013). The Measurement of Maximal (Anaerobic) Power Output on a Cycle Ergometer: A Critical Review. Journal of Biomedicine and Biotechnology
Duche, P., G. Falgairette, M. Bedu, G. Lac, A. Robert, and J. Coudert. (1993). Analysis of Performance of Prepubertal Swimmers Assessed From Anthropometric and Bio-Energeticcharacteristics. Eur J Appl Physiol Occup Physiol. 66, 5, pp. 467-471

Dushkov, V., and Stefanova, D. (1983). Cycle ergometer's test for anaerobic work capacity assessment. Coachings' Thought. 2, pp. 41-46.

Forbes, S., Kennedy, M., Boule N., and Bell, G. (2014). Determination of the Optimal Load Setting for Arm Crank Anaerobic Testing in Men and Women. International Journal of Sports Medicine. 35, 10, pp. 835-839.

Gullstrand, L. (2000). Swimming as an Endurance Sport. In Endurance in Sport by R. Shephard and P. Astrand: pp. 824-835.

Hawley, J., Williams, M., Vickovic, M. and Handcock, P. (1992). Muscle Power Predicts Freestyle Swimming Performance. Brit J Sport Med. 26, 3, pp. 151-155.

Inbar, O., and Bar-Or, O. and Skinner, G. (1996). The Wingate Anaerobic Test. Human Kinetics, Champaign Illinois: pp. 8-9.

Izov, N. (2017). Training loadings in the sport swimming, NSA PRESS, Sofia, pp. 1920.

Lovell, D., Kerr, A., Wiegand, S., Solomon, C., Harvey, L. and McLellan, C. (2013). The Contribution of Energy Systems During the Upper Body Wingate Anaerobic Test. Appl Physiol Nutr Metab. 38, pp. 216-219.

Peres, G., Vandewalle, H. and Monod, H. (1981). Aspect Particulier de la Relation Charge-Vitesse Lors du Pédalage sur Cyclo-Ergomètre, J Physiol (Paris): 77, pp. 10.

Pirnay, F., and Crielaard, J. (1979). Mesure de la Puissance Anaerobie Alactique. Mcdecinc de Sport. 53, pp. 13-16. Sargeant, A., and Davies, C. (1977). Forses Applied to Cranks of a Bicycle Ergometer During One- and Two-Leg Cycling. Journal of applied phisioligy. 42, pp. 514-518.

Szogy, A., and Charebetiu, C. (1974). Minutetest auf dem Fehradergometer zur Bestimmung der Anaeroben Kapazitat. European Journale of Applied Phisisology. 33, pp. 171-176.

Szogy, A., Bohmer, D., Ambrus, P. and Braune, S. (1984). Zur Bestimmung der Anaeroben Kapazität bei Radrennfahrern. Ditsch. Z. für Sportmedizin. 5, 35, pp. 153-160.

Shimoyama, Y., Wada, T., Aoki, Y. (2018). Aoki Physiological responses to high-intensity exercises using tethered swimming and Wingate cycling in competitive swimmers. Journal of Science and Medicine in Sport. 21, pp. 84.

Corresponding author: Mihail Kachaunov National Sports Academy "Vassil Levski", Aquatic sports department Studentski Grad, 1700 Sofia, Bulgaria, E-mail: mihail.kachaunov@gmail.com 